\title{
El ciberlenguaje juvenil universitario: Análisis de los textos de la página de Facebook "Confesiones"
}

\section{Cyber Language used by University Syudents: Textual Analysis of Facebook page "Confessions"}

Dennis Arias Chávez*1 (iD Universidad Continental, Arequipa, Perú ORCID: https://orcid.org/0000-0003-1500-8366

Teresa Ramos Quispe Universidad Continental, Arequipa, Perú ORCID: https://orcid.org/0000-0003-4607-4745

Luis Alberto Núñez Lira Universidad Cesar Vallejo, Lima, Perú Universidad Nacional Mayor de San Marcos, Lima, Perú ORCID: https://orcid.org/0000-0003-4607-4745

Miguel Gerardo Inga Arias Universidad Nacional Mayor de San Marcos, Lima, Perú ORCID: https://orcid.org/0000-0002-1588-0181

Recibido 20-13-18 Revisado 02-04-18 Aprobado 10-08-17 En línea 22-08-18

*Correspondencia
Email: darias@continental.edu.pe

Citar como:

Arias, D., Ramos T., Núñez, L., \& Inga, M. (2018). El ciberlenguaje juvenil universitario: Análisis de los textos de la página de Facebook "Confesiones". Propósitos y Representaciones, 6(2), 339-405. Doi: http://dx.doi.org/10.20511/ pyr2018.v6n2.238

(C) Universidad San Ignacio de Loyola, Vicerrectorado de Investigación, 2018

(cc) BY-NC-ND Este artículo se distribuye bajo licencia CC BY-NC-ND 4.0 Internacional (http://creativecommons.org/licenses/by-nc-nd/4.0/). 


\section{Resumen}

La presentación del ciberlenguaje como una de las variantes de la lengua incluye una discusión sobre su carácter como forma intermedia entre la oralidad y la escritura y las fuerzas responsables de los cambios lingüísticos. Por una parte, la vertiente popular que ha dado origen a la evolución constante de la lengua; y por otra, la culta que se esfuerza por recuperar la forma etimológica (Betancourt, 2010). El objetivo del presente estudio es analizar los fenómenos lingüísticos presentes en los textos que figuran en la página de Facebook denominada "Confesiones" de 6 universidades peruanas: tres arequipeñas y tres filiales de universidades limeñas en esta ciudad. El corpus de análisis consta de 70 textos, el diseño es descriptivo transversal de tipo documental y como instrumento se utilizó una ficha de registro de variaciones lingüísticas en la que se recogen y analizan los rasgos ortográficos, léxicosemánticos, léxico-sintácticos, además de la función que cumple el lenguaje utilizado en este medio. El estudio evidencia la existencia de una variedad heterogénea con un marcado carácter creativo de los textos. En lo que se refiere a los rasgos ortográficos, destacan la elisión de vocales, sustitución y multiplicación de grafemas consonánticos. Los rasgos léxico-semánticos de los textos analizados muestran un marcado uso de eufemismos, palabras coloquiales y anglicismos. Desde el punto de vista léxico-sintáctico, el análisis muestra que, pese al carácter más o menos informal del medio que se utiliza (Facebook), los mensajes que se transmiten son textos que desarrollan argumentaciones completas y complejas. Finalmente, las funciones que prevalecen en los textos son la emotiva y fática.

Palabras clave: Ciberlenguaje, recursos lingüísticos, intencionalidad comunicativa, Facebook. 


\section{Summary}

The presentation of the cyber language as one of the variations of the language includes a discussion on its nature as an intermediate form between oral language and written language and the forces responsible for the linguistic changes. On the one hand, we have the popular usage that has given rise to the constant evolution of the language and, on the other hand, the educated speech which strives to recover its etymological form (Betancourt, 2010). The objective of the present study is to analyze the linguistic phenomena present in the texts listed on the Facebook page called "Confessions" of 6 Peruvian universities, 3 from the city of Arequipa and 3 subsidiaries of Lima universities in this city. The corpus consists of 70 texts, the design is transversal, descriptive and documentary and we used as a tool a registration form of linguistic variations in which spelling, lexical-semantic and lexicalsyntactic features were collected and analyzed, in addition to the function of the language used in this means. The study demonstrates the existence of a different variety of distinctly creative texts. Regarding the spelling features, we found the vowel elision, substitution and multiplication of consonant graphemes. Lexical-semantic features of the analyzed texts show a marked use of euphemisms, colloquial words and anglicisms. From the lexical-syntactical point of view, the analysis shows that despite the more or less informal nature of the means used (Facebook), the messages that are transmitted are texts which develop comprehensive and complex argumentations. Finally, functions that are prevalent in the texts are the emotional and phatic ones.

Keywords: Cyber language, linguistic resources, communicative intent, Facebook. 


\section{Introducción}

Todo organismo vivo busca integrar elementos de su entorno con el fin de poder sobrevivir a él. Este proceso de integración no solo se da a nivel biológico, sino también en lo social. Sin duda el internet representa mejor que otros fenómenos este proceso que ha llevado a las sociedades a transitar de una realidad física a una virtual. La capacidad que tiene el internet de generar información parece no tener límites y su presencia sigue expandiéndose por todo el mundo a una velocidad incré́ble. Es tanta su importancia, que se ha convertido en una herramienta indispensable no solo para la población académica y profesionalmente activa, sino también para cualquiera que tenga acceso a ella (Raacke \& Bonds-Raacke, 2008).

El advenimiento de la tecnología ha generado cambios no solo en las personas, sino también en la misma sociedad. La necesidad que todo ser humano tiene de formar parte de grupos u organizaciones ha sido llevada a su máxima expresión con la creación de redes virtuales en las que se pueden formar no solo lazos de amistad con otros a los que, en muchos casos, no se conoce, sino también abre las puertas a la posibilidad de mostrarnos al mundo. A estas agrupaciones sociales formadas por personas conectadas por alguna relación común se las conoce como "redes sociales". A este respecto, Fernández (2013) refiere que:

Toda vez que las personas requieren de forma natural establecer comunicación con los demás y las RSI [Redes Sociales en Internet] han roto las barreras del tiempo y espacio para establecer y continuar las relaciones interpersonales por medio del intercambio de ideas, las RSI se han convertido en una importante oportunidad para los usuarios ya que se proveen medios de comunicación asíncrona y síncrona (p. 521).

Las redes sociales, unidas a otras tecnologías, han ampliado la posibilidad de comunicarnos y de vivir conectados socialmente. Su importancia radica en la facilidad que tienen los sujetos de inscribirse en ellas, además de la rapidez con que los mensajes se envían y se reciben. La narrativa que muestran estos 
medios transgrede muchas veces las normas, entre ellas las del idioma, ya que exige anteponer la funcionalidad antes que el cuidado del mensaje.

\section{Tipologías.}

Las redes sociales se clasifican en función del objetivo que persiguen las personas que la integran. La distinción más extendida es la que hace diferencia entre redes generalistas y redes segmentadas (López, 2012). Las primeras se caracterizan por estar enfocadas a todos los usuarios sin distinción de edad, sexo, profesión, etc. Las dos redes más conocidas que forman parte de este grupo son Facebook y Twitter. Tal es el alcance y popularidad de este tipo de redes sociales, que incluso políticos, instituciones e incluso gobiernos las utilizan como medios para llegar a la población. Solo en 2017 la cantidad de usuarios activos en Facebook era de 2.000 millones y esta cifra parece ir en aumento ("Facebook alcanza los 2,000 millones de usuarios", 2017). Por su parte, las redes segmentadas son aquellas que, por una u otra razón, solo se dirigen a un segmento de la población. Este tipo de redes están orientadas a divulgar y compartir información específica entre profesionales de alguna materia científica o técnica. Como ejemplos de estas redes sociales figuran LabRoots, ResearchGates, LinkedIn, entre otras.

\section{Facebook.}

Facebook es una red social cuya arquitectura es sencilla, ya que se basa en conexión de perfiles, en la conexión de personas con personas, que pueden ser familiares, amigos, compañeros de estudio, instituciones o asociaciones. Facebook permite no solo buscar y contactar personas, sino "hacer" amigos tan solo con enviar una solicitud de amistad. Haciendo uso de diferentes aplicaciones, Facebook anima a sus usuarios a compartir sus emociones, imágenes, informar eventos e incluso realizar encuestas y actividades que quedan registradas y que el propio sistema lo recuerda a sus usuarios mediante videos u otras aplicaciones. 
Como resultado de su popularidad, han surgido preocupaciones por el efecto que esta red puede causar a sus usuarios. El ambiente en línea puede llegar a producir comportamientos narcisistas o también modificaciones en la forma de percibir las relaciones amicales, dado el carácter superficial que promueve este medio virtual (Herrera, 2010). El alcance que ha llegado a tener Facebook ha superado toda expectativa dada la forma innovadora de comunicación y socialización que impone. Si bien esta comunicación juega un papel muy importante dentro de las nuevas generaciones, también es importante analizar no solo los cambios sociales, físicos y reales que produce en sus usuarios (Magnuson \& Dundes, 2008), sino también los prejuicios sociales que recaen sobre el uso del lenguaje, en particular sobre el léxico utilizado en las redes sociales, que muchos especialistas consideran pobre. Estos prejuicios responden al espíritu normativo que todos los usuarios de la lengua poseen, y que los lleva a dudar de la competencia lingüística de los usuarios de estas redes sociales.

\section{Las páginas de confesiones de Facebook.}

Confesarse es el acto de declarar o reconocer un error, falta o delito, por lo general frente a alguien que ejerce el poder de perdonar. Y aunque este término está relacionado con la religión o la justicia, podemos extrapolar este acto a nuestra vida diaria. En estos últimos años la tendencia a utilizar las redes sociales, en particular el Facebook, para expresar nuestros sentimientos frente a los demás va en aumento, tendencia que no solo deja aliviado a quien hace la confesión, sino que divierte y hace cómplice a quien la lee.

Las redes sociales se han convertido en un espacio idóneo para intercambiar información, conocimientos y sentimientos de una forma rápida $\mathrm{y}$, hasta cierto punto, superficial. Las posibilidades de generar vínculos sociales mediante la comunicación interpersonal que promueve permiten constituir un sistema de interacción particular y de interés para psicólogos, sociólogos, antropólogos y lingüistas. Expresar lo que estamos pensando o sintiendo posibilita una apertura inusitada en el receptor quien, desde un 
lugar diferente, construye una imagen de "nosotros" en función de "nuestras" palabras. A esta construcción ayuda la inclusión de elementos no lingüísticos como memes, imágenes o emoticones, elementos que refuerzan el mensaje.

Las universidades son espacios académicos donde los estudiantes no solo reciben conocimientos sino también llegan a formarse una identidad profesional. Como toda comunidad humana, los ambientes académicos no están exentos de problemas y situaciones que los estudiantes perciben, muchas veces, como adversas o desafortunadas. Los cursos, los profesores, los compañeros, las instalaciones y la organización de la institución son elementos fundamentales que refuerzan esta percepción. No son pocos los estudios que han demostrado que existen eventos relacionados con la actividad universitaria que generan altos índices de estrés. Entre dichos eventos se pueden mencionar la falta de tiempo para cumplir con sus actividades académicas, la sobrecarga de cursos y actividades, los exámenes, las exposiciones en clase y la realización de trabajos y tareas obligatorias.

Los estudiantes de primer año son los que mayores índices de estrés reportan ante la falta de tiempo para cumplir con las actividades y la sobrecarga académica; factores que, si bien continúan siendo percibidos como estresantes entre los estudiantes de niveles superiores, se ven en algún grado atenuados con el paso del tiempo (Montoya, Gutiérrez, Toro, 2010, p. $10)$.

Son estas vicisitudes las que llevan a los estudiantes a buscar y crear espacios en los que pueden liberar tensiones. Surgen así las páginas de confesiones en Facebook, espacios en los que los usuarios hablan, bajo la etiqueta de "Confieso que...", de diversos temas como, por ejemplo, situaciones amorosas:

Confieso que me gusta la morrita suicida de Arequitectura, siempre para con una chica bajita de lentes, si ves esto hazme caso yo te salvaré

Sobre la percepción que tienen de sus compañeros de estudio: 
Confieso Queeeeeee en la u hay mucho FEOOOO que cree que por ir al "gym" es guapo y lo peor andan con sus poses de machos comiendo su atún, su pollo sus batido de huevo con leche de toro. Bueno quisiera saber que día hacen cara en el GYM hay verdad no pueden cambiar de carabina ni con el cirujano de Milett saludos de arquitectura...

O para solicitar algún tipo de favor o recomendación que incluye además una crítica directa a la institución:

Mano' un favor Publica esto Compañeros Alguna recomendación para estudiar ingles aparte del de la universidad y que el precio sea un poco comodo, \#1 averigüe en la X y esta 130, alguien que recomiende algun otro lugar cultural, britanico o de uno que sepan? \#2 La Universidad debería tener algún convenio con alguna institución de idiomas para los alumnos de la $\mathrm{X}$ grr.

La razón de ser de estas páginas es la de comentar experiencias relacionadas con la universidad. Entre las características que presentan son su anonimato, aspecto que posibilita la libertad de expresión (muchas veces exagerada) de los usuarios, la descontextualización de los mensajes, la posibilidad de responder a las confesiones y de incluir emoticones, memes, videos u otros recursos que refuercen el mensaje. El acceso es libre y lo maneja un administrador, también anónimo. Es común leer en estas páginas comentarios de personas no necesariamente relacionadas con la universidad. Confesiones permite tener la posibilidad de mezclar lo privado con lo público, lo cual hace atractivo a los usuarios, ya que les brinda la posibilidad de hacer suyo lo que otros consideran privado.

\section{Lenguaje de internet o Ciberlenguaje.}

En el entorno virtual, las relaciones entre identidad real e identidad virtual facilitan la creación de personalidades alternas, esto es, la invención de un "yo" virtual dotado de características particulares. A pesar de que esta nueva identidad contiene elementos exagerados e ideales, no dura mucho tiempo, ya 
que pronto se ve superado por el "yo" real. Ahora bien, en lo que respecta al uso del lenguaje en los medios virtuales, existen dos posturas muy marcadas. La primera defiende la irrupción del internet y la variedad de géneros que la red de redes viene creando bajo la categoría de "ciberlenguaje". La segunda afirma que los cambios introducidos por el internet en lugar de enriquecer, empobrecen el idioma.

Cualquier lengua debe adaptarse a las necesidades de sus usuarios, ya que su función primaria es la de expresar nuestra participación, como hablantes, en las diversas situaciones discursivas en las que nos vemos envueltos; la imagen que asumimos frente a nosotros mismos y a los demás; nuestros deseos, sentimiento, actitudes y juicios propios. Sobre este último punto, es importante lo dicho por Halliday (1982), para quien "el lenguaje tiene que interpretar toda nuestra experiencia, reduciendo los fenómenos infinitamente variados del mundo que nos rodea" (p. 33), situación aplicable no solo en el chat, donde los participantes sintetizan ese mundo percibido a partir de sus habilidades tecnológicas, sino también en otros medios virtuales como en los casos del Facebook y Twitter, en los que la exposición a un público es más que evidente. Coseriu (1977) sigue la línea de Halliday, ya que para él el lenguaje es una realidad cultural complejísima, polifacética. La naturaleza viva del lenguaje lo lleva a cambiar y a adaptarse a nuevas situaciones permitiéndole evolucionar de acuerdo con el uso que le dé el hablante.

En los últimos años, el interés por estudiar las variaciones del lenguaje en el internet han priorizado el análisis de los rasgos diferenciales de la norma escrita en diversas plataformas virtuales, como es el caso de conversaciones de WhatsApp (Gómez del Castillo, 2017), Twitter (Sánchez, 2013; Ruiz, 2015) y Facebook (Valderrama, 2013; Medina, 2016), en tanto que los estudios de Covadonga (2006) sobre la comunicación electrónica, el de Rocha (2004) y su estudio sobre el lenguaje de los jóvenes en el chat complementan esta línea de investigación. No obstante, la preocupación también se centra en los mecanismos de escritura que se utilizan en las redes sociales. Como muestra de ello se pueden citar los trabajos de Briz (2014), 
Fuenmayor y Villasmil (2010), Sandoval (2016) y Vanegas (2014). Otro grupo de estudios han fijado sus objetivos en analizar uno de los puntos que mayor polémica genera entre especialistas y usuarios de la lengua: los rasgos ortográficos y los procesos de abreviación de los mensajes producidos en las redes sociales como formas de originalidad y rebeldía; en esta línea tenemos los estudios de Sabando (2017), Figueroa y Quinteros (2016) y Bermúdez, Cabrera y Carranza (2016).

Para referirse de lenguaje de internet se ha venido utilizando el término "ciberlenguaje", el cual se entiende como el código que comparten los usuarios de las redes sociales, especialmente los jóvenes, con el fin de identificarse como parte de un grupo. Entre las características más resaltantes de este código destacan la sencillez, claridad, precisión de los mensajes e inmediatez. Estos rasgos se ponen de manifiesto cuando escribimos en Facebook o en Twitter, redactamos un mensaje de texto o enviamos un mensaje vía WhatsApp. Los estudios existentes sobre el ciberlenguaje advierten un punto en común entre todas sus modalidades, y es el de presentar los discursos como un intento de acercamiento de la oralidad a la escritura (Bertancourt, 2010; Gianmmatteo \& Albano, 2009; Yus, 2001; Gómez, 2001). Este hecho difiere de la forma tradicional de abordar la enseñanza y aprendizaje de la lengua que centra su atención en diferenciar entre lengua escrita y lengua oral. Esta diferencia parece haber desaparecido en el uso de este tipo de lenguaje en el que, si bien aún se conserva la forma escrita, toma un gran número de elementos de la forma oral.

Otro rasgo particular de este tipo de lenguaje es su aproximación a la jerga, ya que difiere del estándar reconocido por la norma, sino más bien constituye lo que se podría llamar "jerga juvenil" (más del 80\% de los usuarios de Facebook se encuentran en un rango de edad de entre 16 a 34 años), puesta al servicio de la autoafirmación de la identidad del grupo, ya que representa una ideología del sentir juvenil, lo que ha llevado a algunos autores a considerarlo como una corriente contracultural (Contreras \& De la Barra, 1996). 
La edad es un factor importante en el llamado lenguaje juvenil, tal y como lo menciona Eckert (1998), quien señala que los recursos lingüísticos utilizados en cualquier edad tienen su propia significación social. Esto lleva a realizar estudios sociolingüísticos de los recursos utilizados por los adolescentes y jóvenes, los mismos que sentarán la base de la comprensión de las variantes lingüísticas utilizadas por los adultos. Los jóvenes utilizan formas particulares de expresión con el fin de identificarse con un grupo particular; para ello utilizan un vocabulario y una fraseología propia que las caracteriza. Otra de las razones que despierta interés en el estudio del lenguaje juvenil, como señala Zimmermann (2002), es que se trata de una cultura idiomática caracterizada por la escasa intervención de las normativas de agentes oficiales, como Academias o instituciones educativas.

Existen rasgos que permiten diferenciar la comunicación que se da en medios virtuales, entre los que figuran: a) su grado de respuesta que es casi inmediata, aunque con ciertas diferencias frente a otros sistemas como el chat o WhatsApp, cuyos textos presentan un ritmo más bien lento, a diferencia de la oralidad; b) no tiene apoyo gestual o prosódico, sin embargo, estas carencias se resuelven con la inclusión de emoticones; c) no permite percibir las reacciones de los interlocutores, aunque los emoticones ayudan a resolver esta limitante; d) el texto puede sufrir variaciones en su estructura e incluso borrarse; e) su grado de descontextualización es alto; f) posee un grado de espontaneidad relativamente alta; g) la complejidad estructural es relativa; h) es susceptible de ser corregido; e i) brinda la posibilidad de enriquecerse con otros recursos (imágenes, fotos, emoticones, gifs, etc.).

\section{Rasgos ortográficos.}

En lo que se refiere a la ortografía y ortotipografía, los textos producidos en las redes sociales se alejan de la norma estándar. Entre las causas que llevan a infringir la normativa ortográfica se encuentran el grado de inmediatez con que se producen los textos y la rapidez de respuesta a estos, lo que lleva a omitir tildes, signos de puntuación, mayúsculas, o incurrir en errores en la 
abreviación de palabras, entre otras faltas, tal y como se puede observar en el siguiente ejemplo:

Tio confe anónimo, soy cachimbo de la VV :'v no se burlen, queria saber si la XX de arequipa esta licenciada y si en el carnet daran como dice esa ley universitaria, para mi la XX es muy buena desde 2do de sec ya quería ir por favor nada de bromas o insultos sean sergios :'v es mi gran duda ya que me llega al Pinocho que mi primo diga que no esta licenciada.

Del ejemplo se puede desprender que la preocupación se centra en el fondo más que en la forma del mensaje, lo que evidencia que existe una desviación intencionada de la norma, no por desconocimiento, pues podemos ver también que algunas palabras sí se escriben correctamente, sino por el interés que tiene el usuario en que su mensaje sea expresado (y rápidamente). Este hecho ha llevado a afirmar que en realidad no se estaría hablando de fallas ortográficas, ya que como condición para que estas existan el usuario tendría que desconocer la norma. Si el usuario conoce la norma pero la omite de manera deliberada, estaríamos frente a un caso de "heterografía", la cual, en palabras de Martínez de Sousa (2004, como se citó en Gómez, 2007), consiste en "desviaciones intencionadas de la norma ortográfica que no se producen por desconocimiento, sino por discrepancias ocasionales con la norma académica" (p. 159).

Este tipo de escritura no genera problemas de comunicación al destinatario, ya que se estructura de manera coherente y cohesionada en razón de que tanto emisor como destinatario comparten las mismas competencias e intereses. Dado que el código constantemente se transforma y reinventa por la creatividad de los hablantes, se está frente a un fenómeno que genera y mantiene sus propias normas. La sanción va por el lado social, mas no representa un impedimento en estas redes.

Giammatteo y Albano (2010) mencionan que la mayoría de errores ortográficos que se comenten en el contexto digital se explican por decisiones 
lingüísticas tomadas por el hablante que responden a la ley del mínimo esfuerzo, a su tendencia a trasladar los rasgos de la oralidad a la lengua escrita y a la creatividad puesta en redactar un tipo de texto diferente del resto. Asimismo, es importante resaltar que pese a la omisión de reglas, el mensaje no se ve afectado, ya que logra su objetivo.

\section{Rasgos léxico-sintácticos.}

Un simple vistazo a los textos producidos en las redes sociales es suficiente para poder hacerse una idea de la peculiaridad de cómo se estructuran las oraciones, sobre todo si se comparan con el modelo escrito estándar. Dentro del paradigma formal, en la descripción lingüística se considera a la lengua como un sistema relativamente acabado, determinado por factores ajenos a su uso y cuya funcionalidad responde a normas más o menos rígidas. Este paradigma lleva a entender que la lengua funciona de manera mecánica. Frente a esta postura se presenta el paradigma funcional, el cual considera que la lengua es un instrumento creado por los hombres para comunicarse. Así como el hombre crea estructuras sociales o familiares con el fin de satisfacer sus necesidades de vivir en sociedad, la lengua también se ve reflejada por estas características ya que responden al uso que de esta se hace. La lengua sirve como medio de comunicación y por ello debe satisfacer las necesidades expresivas del hombre.

La sintaxis es la rama de la lingüística cuyo objeto de estudio son las relaciones que establecen las palabras unas con otras al momento de combinarse para formar unidades superiores en significado. La sintaxis constituye el dominio esencial del sistema de la lengua, es por ello que su alteración, ya sea en orden o estructura, puede hacer peligrar la inteligibilidad del mensaje. Alterar la sintaxis produce, entre otras cosas, distorsiones en la estructura y funcionalidad de las palabras, lo que a la vez puede explicar que la ortografía presente tantas alteraciones (Giammatteo \& Albano, 2010). 
Las diferentes estructuras sintácticas de una lengua se crean para satisfacer necesidades comunicativas concretas. Por tanto, concebir a la sintaxis como un conjunto de reglas estructurales abstractas según las cuales se organiza una lengua no puede considerarse su finalidad última; es el uso lo que ha obligado a los especialistas a reconsiderar esta idea. La utilización sintáctica de palabras y construcciones propias del ciberlenguaje permite acercarla a un tipo de lenguaje coloquial. Esto queda evidente en la brevedad y simpleza de las frases utilizadas en los textos de las redes sociales, rasgos que abundan en el discurso oral, lo cual refuerza una de las características fundamentales de este tipo de lenguaje, que integra características de la forma oral en su estructura.

Es por ello que antes que hablar de una sintaxis incrustada, se puede considerar que el lenguaje en internet usa una sintaxis concatenada en la que los enunciados van acumulándose sucesivamente. Así, es común encontrar desarrollos oracionales como enumeraciones, segmentaciones, yuxtaposición, coordinación y subordinación, o la frecuencia de ampliaciones y reducciones expresivas del núcleo de comunicación (paráfrasis) o rodeos explicativos que determinan la evolución lenta del aporte de información (Pérez, 2012).

Siguiendo a Briz (1996, como se citó en Pérez, 2012), se puede considerar que este tipo de lenguaje recurre a una sintaxis no convencional que linda con lo informal.

\section{Rasgos léxico-semánticos.}

La semántica se ocupa del estudio del significado de las palabras, es decir, de la relación que existe entre los signos con aquello a lo que refieren. El nivel léxico-semántico se ocupa de estudiar los neologismos, el cambio semántico, las siglas, el lenguaje especializado, las jergas, el lenguaje coloquial, los extranjerismos, las frases hechas, los refranes, las figuras retóricas, etc. Como se explicó líneas arriba, el lenguaje usado en la página de Facebook "Confesiones" se caracteriza por el grado de coloquialismo que presenta, ya 
que involucra rasgos que pueden entenderse como transgresiones al uso del idioma, además de que en ella predomina el nivel oral.

Es común que en este tipo de mensajes predominen algunos usos, por ejemplos, el uso de palabras del inglés en frase exclamativa: "Que sad" ('Qué triste', 'Qué pena'); abreviaciones: “XDXDXD” (risas); Empleo de palabra eufemística ("espadita” por 'pene'): "El problema que ambos tenemos espaditas"; voces coloquiales y vulgares: "chupar", “joder”; frases con claras alusiones a la actividad sexual: "me la empujo y sin vaselina"; denominaciones abreviadas: "pasen el face" (por 'facebook'); usos eufemísticos: "Me llega al Pinocho" (por pincho 'pene').

\section{La intención del mensaje y del hablante.}

El carácter coloquial de los textos producidos en las redes sociales resalta algunas funciones del lenguaje como la expresiva y fática. No se deja de lado la función poética, ya que entre las características de este tipo de lenguaje se encuentra la creatividad de los usuarios para producir textos llamativos y originales, siendo la metalingüística la función que menos se aplica en estos textos.

Para el funcionalismo, la lengua es un sistema funcional producto de la actividad humana cuyos propósitos esenciales son la comunicación y la expresión. Roman Jakobson, exponente de este modelo lingüístico, afirma que la comunicación es un proceso con propósitos determinados por un emisor poseedor de intenciones en cuanto a la recepción que quiere que se tenga de su mensaje (Pelayo \& Cabrera, 2001). Jakobson recoge en 1933 la propuesta de Karl Bühler y en su planteamiento las funciones que reconoce son las siguientes: función emotiva, función estética, función conativa, función metalingüistica, función representativa y función fática.

La función lingüística involucra la relación entre destinatario y mensaje, relación que está sujeta a la intención del emisor de construir un enunciado orientándolo hacia cualquiera de los elementos del proceso comunicativo. 
Asimismo, la función que cumple el mensaje está determinada por la forma como la entiende el receptor, así como también el contexto en el que se desenvuelve, ya sea cultural, social o académico. No obstante, en las redes sociales si bien los usuarios comparten el mismo contexto ("la universidad"), no siempre se logra la comprensión de los mensajes, ya que la personalización de los mismos hace que se busque la complicidad de pocos. Por esta razón muchos administradores crean páginas por facultad o escuelas profesionales, con la finalidad de mantener un grupo específico. Esto último se da sobre todo en universidades grandes, en tanto que en universidades relativamente pequeñas es común la existencia de páginas generales.

\section{Metodología.}

La presente investigación aporta un estudio descriptivo que pretende la identificación de los rasgos diferenciadores del lenguaje utilizado en las redes sociales. Para ello se plantearon como objetivos precisar y analizar los rasgos ortográficos, léxico-semánticos y léxico-sintácticos de los textos extraídos del muro de la página de Facebook "Confesiones", y además explicar la finalidad comunicativa de los mismos. Para ello, se utiliza como método de investigación principal el análisis documental de contenidos.

La población estuvo compuesta por 244 textos extraídos del muro de la página de Facebook "Confesiones" de 6 universidades: 3 arequipeñas y 3 limeñas que tienen filial en esta ciudad. Se tomaron los meses de abril, mayo y junio de 2018, meses entre los que se inician las labores académicas y se superan los primeros exámenes parciales. Para la conformación de la muestra se siguió el método no probabilístico intencional, seleccionándose 70 textos. Entre los criterios seguidos para la conformación de la muestra se encuentran: 1) que sean textos extensos aparecidos en el muro de la página (se descartan comentarios hechos a los mismos); 2) textos escritos únicamente por los universitarios (se descartan comunicados u otros textos escritos por oficinas de la propia universidad); 3 ) textos extraídos de las páginas oficiales; y 4) textos que no sean comentarios a memes o imágenes. 
Con respecto a los instrumentos, se crearon dos: la Ficha de registro de los textos, en la que se incluyen datos específicos como fecha de publicación, tema abordado, imagen de respaldo y la trascripción de los textos. Al ser esta ficha de carácter documental no presenta ningún apartado analítico, ya que su función únicamente es la de registrar los datos de la población de estudio. El segundo instrumento fue la Ficha de registro de rasgos lingüísticos creada a partir de la propuesta de Giammatteo y Albano (2009), quienes centran su interés en analizar tres rasgos del ciberlenguaje: ortográfico, morfológico y léxico-semántico. Asimismo, la ficha incluye un rasgo complementario: la función del lenguaje (según Jakobson), rasgo importante para poder adentrarnos en la explicación de la finalidad comunicativa de dicha muestra.

\section{Procedimiento.}

Dadas las características de la población de estudio, la cual corresponde al ámbito universitario, es preciso realizar algunas aclaraciones. Dada la naturaleza anónima de los textos, no se puede determinar rasgos como sexo o edad; y aunque el contexto de las publicaciones pueda ser un indicio de estas características, no es del todo fiable dado el enmascaramiento de los participantes. Recuérdese que entre las características de las redes sociales, se encuentra la de la personalización mediante el uso de una imagen o sobrenombre. Por otra parte, se comprobó, como condición para recolección de los textos, que las páginas en cuestión sean las “oficiales", lo que se logró verificando el número de usuarios y las fechas de publicación de los mensajes. Para comprobar la veracidad de la página se elaboró una ficha de registro de la página en la que se detalla cada uno de estos rasgos. Si bien estas páginas surgen como espacios propios dirigidos no solo a estudiantes universitarios, no hay filtros que evalúen la calidad de los mensajes ni su contenido. Las propias universidades no reconocen estas páginas como oficiales e incluso algunas de ellas prohíben su creación y sancionan a los usuarios en caso se logre reconocer quiénes son. 
Durante el proceso de selección de la muestra se pudo comprobar la tendencia a resumir los mensajes en memes e imágenes, dejando de lado los textos extensos, esto quizá como una manera de ser más expresivos.

Un comentario especial merece el apartado de los comentarios hechos sobre los textos publicados en los muros de las páginas, los cuales suelen ser igual de creativos que los propios mensajes.

El proceso de la selección de la muestra concluyó con la codificación del total de la población de textos recopilados con la finalidad de tener un registro exacto del material, el cual de por sí forma un corpus consistente con el que se podrá contar para futuras investigaciones.

\section{Resultados}

\section{Rasgos ortográficos.}

La inmediatez, junto a la necesidad de escribir a una velocidad mayor que la habitual que en otros medios, hace que exista mayor probabilidad de que se cometan no solo errores ortográficos, sino también ortotipográficos (usos y convenciones que sigue lengua escrita). Entre los rasgos que más destacan en los textos analizados figuran la elisión de vocales, sustitución y multiplicación de grafemas consonánticos y vocálicos (te kiero por "te quiero", mrd por "mierda", $d s d$ por "desde"; te amooooooo por "te amo"). Desde el punto de vista de la imagen que transmite el usuario, este es consciente de que su mensaje está siendo leído por un público quien juzga no solo la forma sino el contenido del mismo. Sin embargo, existe un acuerdo tácito entre destinador y destinatario para poder obviar los errores que se presentan en la escritura de los textos. Predomina sin duda la ansiedad por "confesar" una situación, razón por la que el emisor recurre a estrategias discursivas, como el uso de emoticones (en los textos analizados cumplen una finalidad básica que es la de transmitir conceptos básicos como alegría, tristeza o complicidad) o términos coloquiales, para dotar de rasgos orales a su mensaje. La oralidad 
es un rasgo primario del lenguaje; y en los textos estudiados, parece que hay una tendencia de volver a este principio. El análisis evidencia que el rasgo que predomina en el ciberlenguaje o lenguaje de internet es la ausencia de ortografía. En el Cuadro 1 se presenta una muestra de los textos analizados:

Cuadro 1. Rasgos ortográficos de la nuestra estudiada de la página de Facebook "Confesiones"

\begin{tabular}{|c|c|}
\hline Textos & Rasgos ortográficos \\
\hline $\begin{array}{l}\text { Por favor q sea anónimo.... jajaja .... Confieso, que } \\
\text { si nos han quitado la fiesta por el aniversario de la } \\
\text { Universidad, No debería haber clases, ahora no hay } \\
\text { fiesta, ni feriado, y tenemos a ir a clases, así nos } \\
\text { hacen celebrar... joderrrrr!! XDXDXD }\end{array}$ & $\begin{array}{l}\text { Multiplicación de grafemas consonánticos } \\
\text { con una marcada intención emotiva. }\end{array}$ \\
\hline $\begin{array}{l}\text { Confieso ante todos los compañeros del alas } \\
: \mathrm{v} \text { que me gusta un compañero de psicología } \\
{[\text { [] [ [] }} \\
\text { El problema que ambos tenemos espaditas. } \\
\text { Es taaaaaaan inteligente .... es uno de rulos }\end{array}$ & $\begin{array}{l}\text { Multiplicación de grafemas vocálicos con uso } \\
\text { de emoticones que aumentan la expresividad } \\
\text { del mensaje. }\end{array}$ \\
\hline $\begin{array}{l}\text { Confieso que a mi amigo se le arruga por mandar } \\
\text { este mensaje ... ambos estudiamos admi en la misma } \\
\text { clase pero anda bn hvn por una flaca de ingenieria } \\
\text { Industrial que esta en la ultima clase subiendo las } \\
\text { gradas del baño frente a odonto... no sabemos como } \\
\text { se llama la flaca pero pedimos que nos ayuden a } \\
\text { encontrarla tiene el cabello hasta los hombros y una } \\
\text { mochila cafe, amigaaa a mi amigo le encantaaas } \\
\text { hahahah dice que te vio tambien por el seguro social }\end{array}$ & $\begin{array}{l}\text { Sustitución de grafemas vocálicos y elisión } \\
\text { de vocales con el fin de incrementar la } \\
\text { expresividad. }\end{array}$ \\
\hline $\begin{array}{l}\text { confieso q mi conpañero de industrial se tirara del } \\
\text { puente chilina porque vio la chica q el quiere le dio } \\
\text { un detallazo a su enamorado .... amigo no te tires del } \\
\text { puente valorate jajaja }\end{array}$ & $\begin{array}{l}\text { Sustitución y elisión de grafemas vocálicos } \\
\text { con la intención de enfatizar el mensaje. }\end{array}$ \\
\hline
\end{tabular}

\section{Rasgos léxico-semánticos.}

Las hablas de los jóvenes, en este caso de los universitarios, se caracterizan por alejarse de la norma estándar como una forma de alejarse de la forma de hablar etiquetada como "correcta", que los jóvenes ven asociada a la imagen de la generación mayor. Esta actitud es reforzada por el uso de otros recursos como son los emoticones, memes, imágenes, etc. La idea de que 
los jóvenes configuren, a pequeña escala, una contrasociedad o antisociedad (Rodríguez, 2002) les será importante en la configuración de un sistema de comunicación propio que traslade sus valores, sentimientos y frustraciones, además de servirles como una forma de identidad. Para lograr este propósito crean nuevas palabras, deforman otras o les asignan acepciones nuevas a las ya existentes. O bien toman palabras extranjeras o del habla marginal de una marcada connotación peyorativa. Estos cambios del vocabulario son denominados por Halliday (1978) “sobrelexicalización”.

Otro aspecto importante de resaltar es el carácter efímero de las expresiones utilizadas en estos medios. Lo normal es que su inclusión en el lenguaje varíe con el tiempo, como es el caso de las jergas. La elección de uno u otro término obedece a los cambios culturales y al propio estado de ánimo del usuario, característica que también se ve reflejada en el campo conceptual en el que se inscriben los mensajes: amor, sexo, trato social... En el Cuadro 2 se recogen algunos de estos fenómenos: 
Cuadro 2. Rasgos léxico-semánticos de la nuestra estudiada de la página de Facebook "Confesiones"

\begin{tabular}{|c|c|c|}
\hline Textos & Rasgos léxico-semántico & Campos conceptuales \\
\hline $\begin{array}{l}\text { Confieso que los pabellones A y } \\
\text { B... JAMAS tienen papel higié- } \\
\text { nico... Que sad... }\end{array}$ & $\begin{array}{l}\text { Palabra del inglés en frase } \\
\text { exclamativa: } \\
\text { Que sad ('Qué triste', 'Qué pena') }\end{array}$ & Emociones \\
\hline $\begin{array}{l}\text { Confieso ante todos los } \\
\text { compañeros del alas } \\
\text { gusta un compañero de psicología } \\
\text { El problema que ambos tenemos } \\
\text { espaditas. } \\
\text { Es taaaaaaan inteligente .... es uno } \\
\text { de rulos }\end{array}$ & $\begin{array}{l}\text { Empleo de palabra eufemística } \\
\text { (espadita por 'pene') } \\
\text { El problema que ambos tenemos } \\
\text { espaditas. }\end{array}$ & Sexo \\
\hline $\begin{array}{l}\text { Confieso que los de industrial son } \\
\text { unos envidiosos de mierda, que } \\
\text { no tiene flacas para chupar por } \\
\text { eso joden tanto ... hagan espaditas } \\
\text { noma ma...., chupense mi DSM-5 } \\
\text { att. Los borrashos de psicología } \\
\text { y odonto } \\
\text { Anonimo }\end{array}$ & $\begin{array}{l}\text { Voces coloquiales y vulgares } \\
\text { chupar, joder } \\
\text { Anglicismo } \\
\text { chupense mi DSM-5 (Diagnostic } \\
\text { and Statistical Manual of Mental } \\
\text { Disorders 'Manual de diagnóstico } \\
\text { y estadísticas de transtornos } \\
\text { mentales') }\end{array}$ & $\begin{array}{l}\text { Licor } \\
\text { Salud } \\
\text { Extranjerismo }\end{array}$ \\
\hline $\begin{array}{l}\text { Estoy apunto de confesar que en } \\
\text { el examen de civil de segundo año } \\
\text { mi profesor me la empujo y sin } \\
\text { vaselina en el examen. } \\
\text { Anónimo pesh } \\
\text { Saludos a los de ing civil } \\
\text { :v cachimbos... les va a doler } \\
\text { a a }\end{array}$ & $\begin{array}{l}\text { Alusión a actividad sexual } \\
\text { me la empujo y sin vaselina } \\
\text { Uso de emoticonos } \\
\text { e }\end{array}$ & Sexo \\
\hline $\begin{array}{l}\text { Confieso que quiero saber si Yaz- } \\
\text { min Romina de Industrial tiene } \\
\text { flacoo. me gusta, y quisiera que } \\
\text { me ayuden con esto herman@s. }\end{array}$ & $\begin{array}{l}\text { Palabra coloquial y juvenil } \\
\text { flacoo ('enamorado') } \\
\text { Empleo de la arroba para hacer } \\
\text { explícita la alusión a los dos sexos y } \\
\text { evitar la repetición de una palabra en } \\
\text { masculino o en femenino. }\end{array}$ & Trato social \\
\hline
\end{tabular}




\begin{tabular}{|c|c|c|}
\hline $\begin{array}{l}\text { Tio confe anónimo, soy cachimbo } \\
\text { de la VV :'v no se burlen, queria } \\
\text { saber si la XX de arequipa esta } \\
\text { licenciada y si en el carnet daran } \\
\text { como dice esa ley universitaria } \\
\text {, para mi la XX es muy buena } \\
\text { desde 2do de sec ya quería ir por } \\
\text { favor nada de bromas o insultos } \\
\text { sean sergios :'v es mi gran duda } \\
\text { ya que me llega al Pinocho que mi } \\
\text { primo diga que no esta licenciada. }\end{array}$ & $\begin{array}{l}\text { Palabra tabú } \\
\text { me llega al Pinocho que (por pincho } \\
\text { 'pene') } \\
\text { Uso de emoticono } \\
\text { :'v } \\
\text { Uso de vocativo: } \\
\text { Tío confe }\end{array}$ & Sexo \\
\hline $\begin{array}{l}\text { :Soy estudiante de arquitectura } \\
\text { de una u local, tengo } 23 \text { y soy } \\
\text { hetero curiosa. Hay un chico } \\
\text { q quiero mucho y cada cierto } \\
\text { tiempo me visita, nos conocemos } \\
\text { ya varios años, él es de Lima, } \\
\text { tiene } 27 \text {, estudia en la pucp y es } \\
\text { lindo, simpático y super buena } \\
\text { onda, educado, inteligente y nos } \\
\text { llevamos muy bien, nos queremos } \\
\text { muchísimo y nos llevamos muy } \\
\text { bien en todo, sobretodo en el sexo, } \\
\text { es x eso q a ambos nos gustaría } \\
\text { experimentar un 3some, conocer } \\
\text { a una chica super buena onda, } \\
\text { linda, open mind y alegre, con } \\
\text { ganas de experimentar juntos y } \\
\text { q tmb sienta curiosidad x estas } \\
\text { cosas, todo con mucha buena } \\
\text { vibra y full discreción para pasarla } \\
\text { genial. A ambos nos gusta mucho } \\
\text { salir, viajar y pasarla super. Si hay } \\
\text { alguna chica bi o heterocuriosa } \\
\text { como yo q esté interesada, q deje } \\
\text { su me encanta y la contactamos o } \\
\text { simplemente q comente. Gracias } \\
\text { x la buena onda, vibrass a todosss }\end{array}$ & $\begin{array}{l}\text { Palabras alusivas a actividad sexual } \\
\text { hetero curiosa, 3some (threesome } \\
\text { 'trío'), bi o heterocuriosa } \\
\text { Anglicismos } \\
\text { open mind, 3some, full discreción } \\
\text { Ponderación } \\
\text { super buena onda, pasarla super } \\
\text { Invitación } \\
\text { q deje su me encanta } \\
\text { Neologísmo } \\
\text { Heterocuriosa }\end{array}$ & $\begin{array}{l}\text { Sexo } \\
\text { Extranjerismo } \\
\text { Comunicaciones }\end{array}$ \\
\hline $\begin{array}{l}\text { Hola Tio CONsolador } \\
\text { Quiero confesar que me gusta } \\
\text { una flaquita bien rikolina de } \\
\text { sistemas,se llama Keysi, desde } \\
\text { aquella vez que la vi, alla en el } \\
\text { comedor de industrial por primera } \\
\text { vez me vacié ... } \\
\text { solito el vaso de chicha, ya que su } \\
\text { sonrisa me desconcentró,esos len- } \\
\text { tecitos me matan XD ,A veces voy } \\
\text { a la cancha de electronica y espero } \\
\text { sentado horas hasta poder verla, } \\
\text { ni siquiera sé su horario y eso me } \\
\text { pone super sad :"( si bien estoy un } \\
\text { poco chancado, tengo buenos mo- } \\
\text { masos para conquistarla,y quién } \\
\text { sabe podamos abrir una cabina } \\
\text { juntos, para que sea nuestro nidito } \\
\text { de amor. }\end{array}$ & $\begin{array}{l}\text { Anglicismo } \\
\text { super sad } \\
\text { Palabra coloquial insinuada } \\
\text { me vacié }[\ldots] \text { el vaso de chicha } \\
\text { Abreviaciones } \\
\text { XD (risas) } \\
\text { Vocativo } \\
\text { Tío CONsolador }\end{array}$ & $\begin{array}{l}\text { Emociones } \\
\text { Sexo }\end{array}$ \\
\hline
\end{tabular}




\section{Rasgos léxico-sintácticos.}

Desde el punto de vista léxico-sintáctico, el análisis de los textos demuestra que pese al carácter más o menos informal del medio que se utiliza (Facebook), los mensajes que se transmiten son textos que desarrollan argumentaciones completas y complejas.

A diferencia, por ejemplo, de los mensajes de texto en teléfonos móviles, los de Facebook permiten mensajes de extensión suficiente para el uso de los interesados. En la muestra tenemos mensajes desde 13 hasta 138 palabras. Esto da oportunidad para que el usuario exponga y argumente con relativa facilidad y claridad lo que desea comunicar. Es así que en el corpus es posible encontrar oraciones pequeñas, como en el siguiente texto: "estoy enamorado de feer de psicología lo llevo vijilando un tiempo amigos ayuda", que tienen una sintaxis clara, en este caso dos oraciones yuxtapuestas (no tienen conector) y un vocativo.

Por otro lado, es significativo que de 70 ejemplos de la muestra, 45 tengan la conjunción subordinante que, lo cual indica un predominio de oraciones compuestas. Se presentan 7 conjunciones causales (cuatro porque y tres ya que), dos veces la conjunción concesiva así (equivalente de aunque, en el ejemplo 14) y dos conjunciones adversativas pero. Hay cinco ejemplos de uso del adverbio relativo cuando, que siempre es marca de oración subordinada (dentro de una oración compuesta)

También es interesante la presencia (ejemplo 15) de una oración subordinada inserta entre paréntesis: "Llegué a ver su nombre cuando puso su correo (no soy acosador), era dara o algo así”, lo que demuestra la variedad de estructuras de las que hacen uso los usuarios en dicha página.

El que se recurra a todos estos elementos sintáctico-gramaticales indica que pese a una relativa precariedad (en tiempo y espacio para escribir) que experimentan los participantes, estamos ante una forma completa de discurso, tanto en el sentido en que se concretan variadísimas formas de expresión, como por la posibilidad de respuesta del aludido o cualquier otro 


\section{interesado en la comunicación. En el Cuadro 2 se recogen las características} sintácticas de la nuestra estudiada:

\section{Cuadro 3. Características sintácticas de la nuestra estudiada de la página de Facebook "Confesiones"}

Con conjunción subordinante oracional que

\section{Texto 13}

Tio confe te confieso que yo soy el zuculento que para caminando por la Universidad

Con porque

Texto 34

ni vayas ala fiesta de la u porque nadiess te va a salvar

Con pero

\section{Texto 14}

podíamos adelantar el parcial [...] al martes, pero por un par de imbéciles que no firmaron un papel de mrd no lo van a cambiar

Con conjunción subordinante oracional si

Texto 41 Y nose si un alma bondadosa quiera venderme su libro

Con cuando

Texto 33 Todo anda bien cuando no vienes

Con pronombre exclamativo qué

Texto 36 q facil eres compañera

Con pronombre interrogativo qué

Texto 43 nose que paso en la madrugada

Texto 44 Que tiene que ver el fútbol con la universidad

Con pronombre interrogativo quién

Texto 48 pleasee digame quien es

Con pronombre relativo que

Texto 42 su profesor como buena persona $k$ es los hara viajar juntos

Texto 50 hubo un chico que estaba rikolino

Con pronombre personal fuera de posición normal

Texto 10 porfavor la necesito localizar (por 'necesito localizarla')

Con oraciones yuxtapuestas

Texto 18 esta es una confe de un antiguo amor de academia, yo estudie un ciclo en la mendel para poder ingresar a la chunsa, entonces en ese periodo encontre a una chica muy linda y tierna

Con oración coordinada (oraciones enlazadas por conjunción)

Texto 15 estaba en la SanPa imprimiendo en el primer piso, y vino una chica de lentes y cabello café largo

Con amalgama o fusión

Texto 40 na mas wa decir (por 'voy a decir' (< vua decir)) 


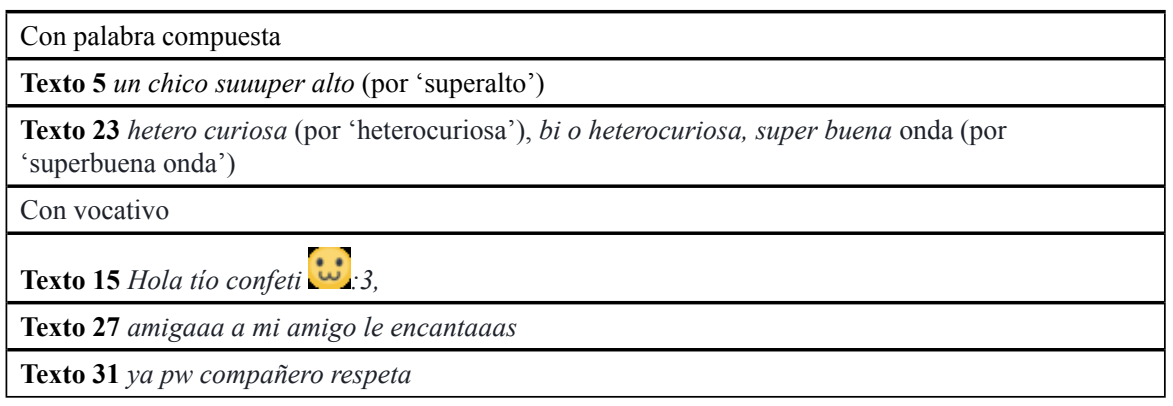

\section{Intención comunicativa}

En los casos estudiados, debemos señalar que la función que menos se manifiesta en los mensajes es la metalingüística (aquella en que se habla sobre el lenguaje mismo), con un solo ejemplo, el $\mathbf{4 6}$ (“***no sabia que tener flaco y estar con alguien eran totalmente distintos jajajjajajajajjajaja”). En primer lugar, se tiene la función apelativa, siendo las funciones recurrentes en todos los textos la función expresiva y la función conativa, lo que las convierte en las funciones primarias de los textos analizados. Asimismo, en cuanto al uso de verbos, predominan el modo imperativo e indicativo, la segunda persona y el uso de vocativos. El aspecto creativo está representado por la función poética aunque esta queda absorbida, junto con la representativa, por la función expresiva. En el Cuadro 4 se recogen algunas muestras del fenómeno. 
Cuadro 4. Intención comunicativa presentes en los textos de la página de Facebook "Confesiones"

\begin{tabular}{|c|c|c|c|}
\hline Textos & $\begin{array}{c}\text { Funciones que } \\
\text { interactúan }\end{array}$ & Intención & Finalidad \\
\hline $\begin{array}{l}\text { Confieso que el pabellon } \mathrm{F} \\
\text { es el mas cochino de todos... } \\
\text { Hasta con*** andan botando, } \\
\text { jaja y los profes se rien nomas } \\
\text { jajaja }\end{array}$ & $\begin{array}{ll}\text { a. } & \begin{array}{l}\text { Expresiva o } \\
\text { emotiva }\end{array} \\
\text { b. } & \text { Conativa }\end{array}$ & $\begin{array}{l}\text { El emisor } \\
\text { expresar } \\
\text { opiniones y } \\
\text { vivencias. } \\
\text { confieso apara } \\
\text { delimitar } \\
\text { su mensaje } \\
\text { personalizándolo. }\end{array}$ & $\begin{array}{l}\text { Manifestación } \\
\text { subjetiva de la } \\
\text { realidad } \\
\text { Interés por llamar } \\
\text { la atención del } \\
\text { destinatario }\end{array}$ \\
\hline $\begin{array}{l}\text { Por favor q sea anónimo.... } \\
\text { jajaja .... Confieso, que si nos } \\
\text { han quitado la fiesta por el } \\
\text { aniversario de la Universidad, } \\
\text { No debería haber clases, aho- } \\
\text { ra no hay fiesta, ni feriado, y } \\
\text { tenemos a ir a clases, así nos } \\
\text { hacen celebrar... joderrrrr!! } \\
\text { XDXDXD }\end{array}$ & $\begin{array}{ll}\text { a. } & \begin{array}{l}\text { Expresiva o } \\
\text { emotiva }\end{array} \\
\text { b. } & \text { Conativa }\end{array}$ & $\begin{array}{l}\text { El emisor } \\
\text { expresar su } \\
\text { opinión sobre } \\
\text { un problema en } \\
\text { particular. } \\
\text { Usa la expresión } \\
\text { Por favor q sea } \\
\text { anónimo con } \\
\text { el fin de que su } \\
\text { opinión no sea } \\
\text { sancionada. } \\
\text { Inicia o continua } \\
\text { la comunicación } \\
\text { haciendo uso de } \\
\text { una expresión } \\
\text { que da inicio a su } \\
\text { discurso y el uso } \\
\text { de emoticonos } \\
\text { para concluirlo. }\end{array}$ & $\begin{array}{l}\text { Manifestación } \\
\text { subjetiva de la } \\
\text { realidad } \\
\text { Interés por llamar } \\
\text { la atención del } \\
\text { destinatario }\end{array}$ \\
\hline $\begin{array}{l}\text { Estoy apunto de confesar } \\
\text { que en el examen de civil de } \\
\text { segundo año mi profesor me } \\
\text { la empujo y sin vaselina en el } \\
\text { examen. } \\
\text { Anónimo pesh } \\
\text { Saludos a los de ing civil }\end{array}$ & $\begin{array}{ll}\text { a. } & \begin{array}{l}\text { Expresiva o } \\
\text { emotiva }\end{array} \\
\text { b. } & \text { Conativa }\end{array}$ & $\begin{array}{l}\text { Expresar } \\
\text { opiniones y } \\
\text { vivencias } \\
\text { Inicia la } \\
\text { comunicación } \\
\text { estimulando el } \\
\text { interés del lector. } \\
\text { Uso de } \\
\text { emoticones } \\
\text { para reforzar la } \\
\text { expresividad del } \\
\text { mensaje. }\end{array}$ & $\begin{array}{l}\text { Manifestación } \\
\text { subjetiva de la } \\
\text { realidad } \\
\text { Interés por llamar } \\
\text { la atención del } \\
\text { destinatario }\end{array}$ \\
\hline $\begin{array}{l}\text { Jajaja, esta es de mi amiga: } \\
\text { confiesa que para aprobar } \\
\text { bioestadística, recurrió a sus } \\
\text { recursos y el profe Cedió... }\end{array}$ & $\begin{array}{ll}\text { a. } & \text { Expresiva o } \\
\text { emotiva } & \text { Conativa }\end{array}$ & $\begin{array}{l}\text { Expresa vivencias } \\
\text { ajenas } \\
\text { Inicia la } \\
\text { comunicación } \\
\text { estimulando el } \\
\text { interés del lector } \\
\text { dejando entrever } \\
\text { una connotación } \\
\text { sexual del } \\
\text { mensaje. } \\
\text { Se aleja del } \\
\text { contenido } \\
\text { asignando la } \\
\text { responsabilidad } \\
\text { a un tercero, } \\
\text { en este casi su } \\
\text { amiga. }\end{array}$ & $\begin{array}{l}\text { Manifestación } \\
\text { subjetiva de la } \\
\text { realidad } \\
\text { Interés por llamar } \\
\text { la atención del } \\
\text { destinatario }\end{array}$ \\
\hline
\end{tabular}




\begin{tabular}{|c|c|c|c|c|}
\hline $\begin{array}{l}\text { Confieso que el docente de } \\
\text { la facultad ciencias contables } \\
\text { y financieras con apellido.... } \\
\text { se deja sobronar y aprueba a } \\
\text { chicas que tengan ..... con el. } \\
\text { No es justo debrian votarlo } \\
\text { de la u. }\end{array}$ & & $\begin{array}{l}\text { Expresiva o } \\
\text { emotiva } \\
\text { Conativa }\end{array}$ & $\begin{array}{l}\text { El mensaje } \\
\text { tiene un carácter } \\
\text { de denuncia } \\
\text { aunque con bases } \\
\text { subjetivas. El } \\
\text { uso de la frase } \\
\text { "Confieso que" } \\
\text { permite iniciar la } \\
\text { comunicación }\end{array}$ & $\begin{array}{l}\text { Manifestación } \\
\text { subjetiva de la } \\
\text { realidad } \\
\text { Interés por llamar } \\
\text { la atención del } \\
\text { destinatario }\end{array}$ \\
\hline $\begin{array}{l}\text { Tengo ganas de circuncidarme } \\
\text { con una cuchara de plástico } \\
\text { el parcial que tenemos a la } \\
\text { hora del al martes, } \\
\text { pero por un par de imbéciles } \\
\text { que no firmaron un papel } \\
\text { de mrd no lo van a cambiar } \\
\text { ptmr así no te guste el fútbol } \\
\text { que par de egoístas, todo el } \\
\text { puto país se para por esto y a } \\
\text { esos } 2 \text { miserables se la suda } \\
\text { entera. Así tengan } 3 \text { exámenes } \\
\text { como yo, que no jodan, es } \\
\text { el encuentro deportivo más } \\
\text { importante de nuestro país en } \\
\text { años y por un examen de un } \\
\text { curso de mrd, ptmr que ganas } \\
\text { de mearles en la cara. Gracias } \\
\text { por su atención. }\end{array}$ & a. & $\begin{array}{l}\text { Expresiva o } \\
\text { emotiva } \\
\text { Conativa }\end{array}$ & $\begin{array}{l}\text { Manifestación } \\
\text { subjetiva de la } \\
\text { realidad } \\
\text { Relación } \\
\text { comunicativa } \\
\text { Hace uso de } \\
\text { emoticones } \\
\text { para reforzar la } \\
\text { expresividad de } \\
\text { su mensaje. } \\
\text { Llama la atención } \\
\text { del destinatario } \\
\text { manifestando } \\
\text { realizar una } \\
\text { acción severa en } \\
\text { caso no logre su } \\
\text { objetivo }\end{array}$ & $\begin{array}{l}\text { Manifestación } \\
\text { subjetiva de la } \\
\text { realidad } \\
\text { Interés por llamar } \\
\text { la atención del } \\
\text { destinatario }\end{array}$ \\
\hline $\begin{array}{l}\text { TIITO, Solo digo a los } \\
\text { cachimbos queles falta aun } \\
\text { mucho como para decir el } \\
\text { "confe", todavia no pasaron } \\
\text { por las grandes ligas, ahi se } \\
\text { :v con todo, hasta } 1 \text { oet. } \\
\text { - y como olvid. las almoha- } \\
\text { das con cloro :v }\end{array}$ & a. & $\begin{array}{l}\text { Expresiva o } \\
\text { emotiva } \\
\text { Fática o } \\
\text { contacto }\end{array}$ & $\begin{array}{l}\text { Hace uso de la } \\
\text { frase "Confieso } \\
\text { que" para } \\
\text { iniciar o la } \\
\text { comunicación. } \\
\text { Hace uso de } \\
\text { emoticones } \\
\text { para reforzar la } \\
\text { expresividad de } \\
\text { su mensaje. } \\
\text { Llama la atención } \\
\text { del destinatario } \\
\text { al manifestar la } \\
\text { incapacidad de } \\
\text { los ingresantes a } \\
\text { la universidad. } \\
\text { Utiliza } \\
\text { emoticones } \\
\text { para dar mayor } \\
\text { expresividad a su } \\
\text { mensaje. }\end{array}$ & $\begin{array}{l}\text { Manifestación } \\
\text { subjetiva de la } \\
\text { realidad } \\
\text { Interés por llamar } \\
\text { la atención del } \\
\text { destinatario }\end{array}$ \\
\hline
\end{tabular}




\begin{tabular}{|c|c|c|c|c|}
\hline $\begin{array}{l}\text { Confieso Queeeeeee en la } \\
\text { u hay mucho FEOOOO que } \\
\text { cree que por ir al "gym" es } \\
\text { guapo y lo peor andan con sus } \\
\text { poses de machos comiendo } \\
\text { su atún, su pollo sus batido } \\
\text { de huevo con leche de toro. } \\
\text { Bueno quisiera saber que } \\
\text { día hacen cara en el GYM } \\
\text { hay verdad no pueden } \\
\text { cambiar de carabina ni con el } \\
\text { cirujano de Milett saludos de } \\
\text { arquitectura... }\end{array}$ & a. & $\begin{array}{l}\text { Expresiva o } \\
\text { emotiva }\end{array}$ & $\begin{array}{l}\text { Hace uso de la } \\
\text { frase "Confieso } \\
\text { que" para } \\
\text { iniciar o la } \\
\text { comunicación. } \\
\text { Llama la atención } \\
\text { de su destinatario } \\
\text { al manifestar su } \\
\text { rechazo por cierta } \\
\text { superficialidad } \\
\text { que ostentan sus } \\
\text { compañeros de } \\
\text { estudio. }\end{array}$ & $\begin{array}{l}\text { Manifestación } \\
\text { subjetiva de la } \\
\text { realidad } \\
\text { Interés por llamar } \\
\text { la atención del } \\
\text { destinatario }\end{array}$ \\
\hline $\begin{array}{l}\text { confieso que mi conpañero de } \\
\text { industrial } \mathrm{V} \text { quiere atrazar o } \\
\text { darle serrucho serrucho a su } \\
\text { amigo con su flaca de derecho } \\
\text {... ya pw compañero resp } \\
\end{array}$ & & $\begin{array}{l}\text { Expresiva o } \\
\text { emotiva } \\
\text { Conativa }\end{array}$ & $\begin{array}{l}\text { Hace uso de la } \\
\text { frase "Confieso } \\
\text { que" para } \\
\text { iniciar o la } \\
\text { comunicación. } \\
\text { Hace uso de } \\
\text { emoticones } \\
\text { para reforzar la } \\
\text { expresividad de } \\
\text { su mensaje. } \\
\text { Llama la atención } \\
\text { de su destinatario } \\
\text { al delatar el deseo } \\
\text { de uno de sus } \\
\text { compañeros. }\end{array}$ & $\begin{array}{l}\text { Manifestación } \\
\text { subjetiva de la } \\
\text { realidad } \\
\text { Interés por llamar } \\
\text { la atención del } \\
\text { destinatario }\end{array}$ \\
\hline
\end{tabular}

\section{Discusión}

En la actualidad, el internet y sus diferentes aplicaciones vienen cambiando las formas de comunicación. Las prácticas de la escritura y la lectura tal y como las conocíamos han sufrido ciertas modificaciones. La aparición de la televisión, en su momento, representó un peligro para los ámbitos académicos dado el papel de los medios para el aprendizaje del lenguaje. Sin embargo, todos estos temores se han trasladado al internet y a su influencia en la formación cultural de los jóvenes, sobre todo en el uso que hacen del lenguaje. No son pocos los que predicen el fin del lenguaje formal como lo conocemos; no pasará mucho tiempo, según ellos, para que el lenguaje se empobrezca e incluso involucione a sus formas más básicas. Como respuesta a esta corriente, existen quienes, de una manera menos apocalíptica, ven estos cambios como una forma más expresiva e incluso contracultural y creativa de usar el lenguaje. El lenguaje no desaparecerá, solo evolucionará como lo ha hecho a lo largo de los años. 
La era de la digitalización impone cambios en los contenidos comunicativos que avanzan de la interiorización a la exteriorización de lo que sentimos, esto es, de mostrarnos al mundo antes que conocernos a nosotros mismos. Esta reestructuración de los contenidos comunicativos tiene su máximo exponente en las redes sociales, medio en el que el lenguaje se orienta ya no solo para transmitir sino para relacionarse. La finalidad de las páginas de Facebook denominadas "Confesiones" es la de compartir experiencias relacionadas con un ámbito específico, en ese caso, el universitario. Entre las características que presentan este tipo de páginas figuran su carácter anónimo, aspecto que posibilita la libertad de expresión (muchas veces exagerada) de los usuarios. También tenemos la descontextualización de los mensajes, la posibilidad de responder a las confesiones y de incluir emoticones, memes, videos u otros recursos que refuercen el mensaje. El acceso es libre y lo maneja un administrador, también anónimo. "Confesiones" permite tener la posibilidad de mezclar lo privado con lo público, lo cual lo hace atractivo a los usuarios, ya que les brinda la posibilidad de hacer suyo lo que otros consideran privado.

En lo que respecta a los rasgos ortográficos presentes en los textos analizados, los resultados coinciden con los estudios que manifiestan que el usuario conoce la norma, pero la omite de manera deliberada (a este fenómeno, como hemos señalado, Martínez de Sousa, (2004, como se citó en Gómez, 2007), llama "heterografía". En conclusión, se puede afirmar que, según lo analizado, la ortografía ha sido despojada de su función normalizadora con el fin de ganar expresividad y creatividad puestas en la construcción de los mensajes.

En lo que se refiere a los rasgos léxico-semánticos, es importante destacar el uso coloquial del lenguaje por parte de los usuarios de estas páginas. En el presente estudio se ha podido observar el uso de palabras del inglés en frases exclamativas, empleo de palabras eufemísticas y voces coloquiales $\mathrm{y}$ vulgares, rasgos que indican que estamos frente a un uso coloquial antes que a uno estándar del lenguaje. Los resultados evidencian que el lenguaje 
usado en la página de Facebook “Confesiones” se caracteriza por el grado de coloquialismo que presentan, ya que involucra rasgos que pueden entenderse como transgresiones al uso del idioma, además de que en ella predomina el nivel oral.

En lo referente a los rasgos léxico-sintácticos, los resultados coinciden con lo dicho por Giammatteo \& Alban (2009), quienes afirman que la utilización sintáctica de palabras y construcciones propias del ciberlenguaje permiten acercarla a un tipo de lenguaje coloquial. Esto se evidencia en la brevedad y simpleza de las frases utilizadas en los textos de las redes sociales, rasgos que abundan en el discurso oral, lo cual refuerza una de las características fundamentales de este tipo de lenguaje que integra características de la forma oral en su estructura, ya que el concepto de clase de palabra, tanto en relación con los requisitos de combinación internos (bases + afijos) como externos o construccionales, se vuelve más permeable y permisivo. Sin duda, existe la intención manifiesta de trasladar las características de la oralidad a la escritura, de acentuar el carácter emotivo-conativo propio de este tipo de comunicaciones y, en todo caso, de hacer gala de las transgresiones propias de la jerga juvenil.

En lo que se refiere a la intención del hablante y del mensaje, destaca el carácter expresivo y persuasivo de los mensajes que absorben a la función representativa y poética, y minimizan la función metalingüística. La función expresiva se plasma en la mayoría de mensajes dada la naturaleza de la página de Facebook analizada. En los textos producidos se pueden observar gran cantidad de signos expresivos como son los vocativos, interjecciones, diminutivos, tono. La subfunción catártica se impone dada la naturaleza coloquial de los mensajes. Por otra parte, la función conativa es esencial en este tipo de mensajes, ya que se pone en evidencia la intención del hablante de llamar la atención de su destinatario, ya sea para hacerle reflexionar, convencerlo o inducirle a asumir parte de su punto de vista.

Un aspecto relacionado con los propósitos expresivos que cumple la página "Confesiones" es su utilidad como un elemento modulador de las 
emociones y estados de ánimo de los participantes, que les alivia tensiones al encontrar en ella un canal en el cual tienen vía libre para expresar sus sentimientos y emociones al mismo tiempo que experimentan una interacción con otras personas, lo cual — si el destinador inicial se ha mostrado extremo en sus opiniones o equivocado - contribuye a que el iniciador de la comunicación asimile las observaciones o críticas de otros, lo que contribuye a mejorar la socialización de la persona.

Quedan algunas dudas con respecto a que si el lenguaje de internet o ciberlenguaje pueda tener impacto en otros ámbitos, como el académico o el laboral, o si su práctica va en desmedro de las competencias comunicativas de los usuarios. Para resolver estos problemas se hace necesario realizar estudios comparativos y explicativos, que darán mayores luces sobre la influencia y proyecciones de este fenómeno.

\section{Referencias}

Bermúdez, F., Cabrera, S., \& Carranza, K. (2016). La influencia de las redes sociales en los cambios de registro ortográfico de los estudiantes de $3^{\circ}$ grado de nivel secundario de I.E.E. $n^{\circ} 81003$ "Cesar A. Vallejo Mendoza" de la Urb. Palermo, Trujillo (Tesis de Licenciatura). Universidad de Trujillo. Recuperado de: http://dspace.unitru.edu.pe/ handle/UNITRU/5297

Betancourt, A. (2010). El ciberlenguaje como variedad lingüística. Revista, Educación, Comunicación, Tecnología, 4(8), 1-19. Recuperada de: https:// revistas.upb.edu.co/index.php/revista_Q/article/viewFile/7807/7126

Briz, A. (2014). Hablar electrónicamente por escrito. Chimera: Romance Corpora and Linguistic Studies 1, 77-89. Recuperado de: https://revistas. uam.es/index.php/chimera/article/view/255/243

Gómez, A. (2007). La ortografía del español y los géneros electrónicos. Comunicar: Revista cientifica iberoamericana de comunicación $y$ educación, 29(15), 157-164. Recuperado de: https://www. revistacomunicar.com/index.php?contenido $=$ detalles\&numero $=29 \&$ arti culo $=29-2007-25$ 
Contreras, C., \& De la Barra, L. (1996). Forma y función de la jerga estudiantil en la ciudad de Temuco. Estudios Filológicos 31, 177-190.

Coseriu, E. (1977). El hombre y su lenguaje. Estudios de teoría y metodología lingüistica. Madrid: Gredos.

Covadonga, A. (2006). El correo electrónico. Estudios de Lingüística del Español. Estudios de Lingüistica del Español, 24, Recuperado de http:// elies.rediris.es/elies24/lopezalonso.htm

Eckert, P. (2008). Variation and the indexical field. Journal of sociolinguistics, 12, 453- 476. Doi: https://doi.org/10.1111/j.1467-9841.2008.00374.x

El Economista. (27 de junio, 2017). Facebook alcanza los 2,000 millones de usuarios. [elconomista.com] Recuperado de: https://www.eleconomista. com.mx/tecnologia/Facebook-alcanza-los-2000-millones-deusuarios-20170627-0013.html

Fernández, E. (2013). Trastornos de conducta y redes sociales en Internet. Salud Mental, 36(6), 521-527. Doi: https://doi.org/10.17711/SM.01853325.2013 .063

Fuenmayor, G. y Villasmil, Y. (2010). Nuevas formas de comunicación juvenil en la producción textual. Interacciones, 16, 90-109. Recuperado de http://www.eses.pt/ interaccoes

Gianmmatteo, M., \& Albano, H. (2009). El español en internet: una mirada a su evolución en los fologs. Revista Digital Universitaria, 10(3), 2-17. Recuperado de: http://www.revista.unam.mx/vol.10/num3/art15/int15. htm

Gómez, L. (2001). La gramática en Internet. Resumen presentado en el II Congreso Internacional de la Lengua Española. Recuperado de http:// congresosdelalengua.es/valladolid/ponencias/nuevas_fronteras_del_ espanol/4_lengua_y_escritura/gomez_l.htm

Gómez del Castillo, M.(2017). Utilización de WhatsApp para la comunicación en titulados superiores. Revista Iberoamericana sobre Calidad, Eficacia y Cambio en Educación, 15(4), 51-65. Recuperado de: https://revistas. uam.es/index.php/reice/article/view/8147

Montoya, L., Gutiérrez, J., \& Toro, B .(2010). Depresión en estudiantes universitarios y su asociación con el estrés académico. Revista CES 
Medicina, 21(1), 7-17. Recuperado de: http://revistas.ces.edu.co/index. $\mathrm{php} / \mathrm{medicina/article/view/1011}$

Halliday, M. A. K. (1978). Language as social Semiotics. Londres: Arnold

Halliday, M.A.K.(1982). El lenguaje como semiótica social. Lainterpretación social del lenguaje y del significado. México: FCE.

Herrera, M., Pacheco, M., Palomar, J., \& Zavala, D. (2010). La adicción a Facebook relacionada con la baja autoestima, la depresión y la falta de habilidades sociales. Psicología Iberoamericana, 18(1), 6-18.

López, J. (2012). Redes sociales. En M. Tascón (Dir.), Escribir en internet. Guía para los nuevos medios y las redes sociales (pp. 151-203). Barcelona: Galaxia Gutenberg.

Magnuson, M., \& Dundes, L. (2008). Gender differences in "Social portraits" reflected in MySpace profiles. Cyberpsychology \& Behavior, 11(2), 239241. Doi: https://doi.org/10.1089/cpb.2007.0089

Medina, D. (2016). El uso del lenguaje escrito empleado en la red social Facebook, por los jóvenes de 15 a 18 años de edad de las parroquias urbanas del Cantón Loja, durante el primer semestre del año 2015 ( Tesis de Licenciatura). Universidad Nacional de Loja. Recuperado de: http://dspace.unl.edu.ec/jspui/handle/123456789/13677

Pelayo, N. y Cabrera, A. (2001). Lenguaje y comunicación. Conceptos básicos, aspectos teóricos generales, características, estructura, naturaleza y funciones del lenguaje y la comunicación. Caracas: CEC.

Pérez, M. (2012). Aproximación a la didáctica de la sintaxis coloquial en bachillerato:elestudiodelasconstruccionesincompletas(TesisDoctoral). Universitat de València Recuperado de https://www.tdx.cat/bitstream/ handle/10803/81890/perezgimenez.pdf?sequence=1\&isAllowed=y

Raacke, J., \& Bonds-Raacke, J. (2008). MySpace and Facebook: Applying the uses and gratifications theory to exploring friend-networking sites. Cyberpsychology \& Behavior, 11(2), 169-174. Doi: https://doi. org/10.1089/cpb.2007.0056

Rocha, A. (2004). El lenguaje de los jóvenes en el chat. Estudios sobre la Cultura Contemporánea, 10(19), 109-140. Recuperado de: http://www. 
culturascontemporaneas.com/anteriores.php? revista $=33 \&$ articulo $=267$ \&page $=6$

Rodríguez, F. (2002). Lenguaje y contracultura juvenil: anatomía de una generación. En F. Rodríguez (Coord.), El lenguaje de los jóvenes (pp. 29-56). Barcelona: Ariel Social.

Ruiz, J. (2015). El lenguaje en el Twitter en los estudiantes de la facultad de Comunicación Social y su incidencia en el ámbito académico (Tesis de Licenciatura). Universidad Central del Ecuador. Recuperado de: http:// www.dspace.uce.edu.ec/handle/25000/5104

Sánchez, P. (2013). Twitter y lenguaje - empobrecimiento del lenguaje en las nuevas tecnologías de la información y comunicación: caso Twitter (Tesis de Licenciatura). Universidad Central del Ecuador. Recuperado de http://www.dspace.uce.edu.ec/handle/25000/2379

Sandoval, S. (2016). Prácticas discursivas de jóvenes en redes sociales (Tesis de Maestría). Universidad de San Buenaventura. Recuperado de http://bibliotecadigital.usb.edu.co/bitstream/10819/3326/1/Practicas discursivas_jovenes_sandoval_2016.pdf

Valderrama, L. (2013). De la escritura en Facebook a la escritura académica (Tesis de Licenciatura). Universidad Pedagógica Nacional. Recuperada de http:/digitalacademico.ajusco.upn.mx:8080/tesis/ handle/123456789/11782

Vanegas, H. (2014). La escritura y las redes sociales (Tesis de licenciatura). Recuperado de: http://hdl.handle.net/123456789/11782

Yus, F. (2001). Ciberpragmática. El uso del lenguaje en Internet. Barcelona: Ariel.

Zimmermann, K. (2007). La variedad juvenil y la interacción verbal entre jóvenes. En F. Rodríguez (coord.), El lenguaje de los jóvenes (pp. 137163). Barcelona: Ariel. 